\section{Daytime sleepiness in patients with type 2 Diabetes Mellitus - a prospective cohort study}

\section{Abstract}

Introduction: Daytime sleepiness is an independent factor for increased health care utilization and all cause mortality. Diabetic patients are more likely to be sleepy during the daytime than non-diabetics.

Objectives: To examine factors influencing the evolution of daytime sleepiness in patients with type 2 diabetes (T2D) in a two-year followup study.

Methods: Patients $(\mathrm{N}=145)$ aged from 40 to 60 of both genders were consecutively recruited and evaluated for comorbidity severity (Charlson Comorbidity Index), depressive symptoms (Beck Depression Inventory, BDI II), sleep quality (Pittsburgh Sleep Quality Index) and physical activity levels (International Physical Activity Questionnaire, IPAQ). Daytime sleepiness was assessed by the Epworth Sleepiness Scale (ESS).

Results: Excessive daytime sleepiness (ESS>10) was found in 51 (35.2\%) patients. At baseline, men had more excessive daytime sleepiness; however, women evolved with more sleepiness after two years. Levels of physical activity were independently associated with excessive daytime sleepiness: patients with a sedentary lifestyle developed worse levels of daytime sleepiness after two years. Active lifestyle was more beneficial for reducing daytime sleepiness in women. In this study, among all patients, levels of physical activity (IPAQ) improved after two years.

Conclusion: Excessive daytime sleepiness affects approximately $1 / 3$ of T2D patients and women evolve with more sleepiness. Better levels of physical activity are independently associated with less daytime sleepiness. Implementing physical exercise possibly break a chain involving sleep-wake alterations and comorbidites in T2D. Gender differences show that these effects are more important for women.
João Paulo Vasconcelos, MD1, Thiago Medeiros C. Daniele, MD1, Pedro Felipe Carvalhedo de Bruin, MD, PhD1, Adriana Costa e Forti MD, PhD', Veralice Meireles Sales de Bruin, MD, PhD

1 Laboratório do Sono e Ritmos Biológicos, Universidade Federal do Ceará, Brazil.

\section{Contact information:}

Thiago M. C. Daniele, MD

ほdanielethiago@yahoo.com.br

\section{Keywords}

diabetes; sleepiness; physical activity; stroke; gender differences. 


\section{Introduction}

Daytime sleepiness is a major public health issue and is an independent factor for increased health care utilization and all cause mortality [1-3] . Previous studies suggest that diabetic patients are more likely to be sleepy during the daytime than non-diabetics [4-6] Patients with type 2 diabetes (T2D) commonly present with sleep abnormalities e.g. restless legs syndrome [7], obstructive sleep apnea [8], circadian alterations [9] and nervous system abnormalities $[10,11]$. Given these evidences, daytime sleepiness in diabetic patients are probably of multifactorial origin.

Obesity and obstructive sleep apnea (OSA) cooccur frequently with T2D $[12,13]$. Furthermore, short sleep duration increases the risk for the development of obesity [14] and is associated with increased incidence of T2D [15]. Importantly, poor sleep quality affects more than half of patients with T2D and relates to depressive symptoms [16]. Arterial hypertension, cerebrovascular events, anxiety, depression, cognitive alterations and dementia are other comorbidities frequent in T2D that potentially influence daytime sleepiness [4, 17-19]. All this evidence demonstrate that these comorbid conditions are multilaterally related.

In T2D, sedentary life contributes to worse anthropometric measures, worse quality of life and more depressive symptoms [20-22]. Considering all this evidence, it is reasonable to investigate the influence of multiple comorbid conditions influencing daytime sleepiness in T2D patients.

The objective of this prospective cohort study is to examine the role of comorbidities and lifestyle factors affecting daytime sleepiness in T2D patients.

\section{Patients and Methods}

\section{Study design}

This is a prospective cohort of patients with T2D from an outpatient tertiary care unit (CIDH) in Fortaleza, Ceará, Brazil. The CIDH provides treatment to approximately 5,000 diabetic patients per month. Initially, 200 patients were recruited and 55 patients were excluded: 38 individuals refused to participate, 5 had recent hospitalization, two were pregnant, and 10 individuals were out of age range of the inclusion criteria. In summary, 145 patients were available after two years follow-up.

Individuals diagnosed for at least one year, of both genders, aged from 40 to 60 years were considered eligible. Patients were excluded if they had any severe comorbidity characterized as the presence of one or more additional diseases or disorders cooccurring, such as renal or hepatic disease, cancer, heart failure, neurological disorder, pregnancy and inability to walk without help for 15 minutes, and/ or did not agree to participate in the study.

The study protocol was approved by the local Research Ethics Committee (HUWC-CEP 031-04-09) and written informed consent was obtained in all cases.

\section{Assessment}

At baseline, in all patients, clinical examination and data were confirmed by chart review [23]. Hypertension was defined as present in those with previous identification of sustained blood pressure 140/90, controlled or uncontrolled, with or without medication [24]. Three previously trained interviewers collected behavior questionnaires, demographic and clinical information using a face-to-face interview. Comorbidity severity was evaluated by the Charlson Comorbidity Index (CCI) [25] previously used in diabetic patients [26], depressive symptoms by the Beck Depression Inventory (BDI II) [27] previously validated [28] and sleep quality by the Pittsburgh Sleep Quality Index (PSQI) [29]. Levels of physical activity were evaluated by the International Physical Activity Questionnaire (IPAQ) [30, 31]. Sedentary behavior is defined as waking activities performed with low energy expenditure and involves sitting or lying down, computer use, TV watching or sitting in a car [32]. 
Two years after initial examination, a phone interview assessed cardiovascular new events and the degree of daytime somnolence by the Epworth sleepiness scale (ESS). The ESS is a validated questionnaire containing eight items that asks for expectation of dozing in eight hypothetical situations. Dozing probability ratings range from zero (no probability) to three (high probability). An ESS score of 10 or more indicates excessive daytime sleepiness [33]. Patients were questioned about new stroke, new cardiac abnormalities, state of hypertension, smoking and alcohol drinking. The primary outcome was the variation in the severity of sleepiness as evaluated by the ESS.

\section{Statistical analysis}

Descriptive statistics are presented as mean \pm standard deviation, range and frequency (\% values). Homogeneity of variance was tested with the Levene's test and normality was tested with the Shapiro-Wilk test. Fisher exact tests for categorical variables, Mann-Whitney $U$ test for continuous variables and Student's t test for normally distributed data with equal variances were performed to compare between cases with and without excessive daytime sleepiness. Logistic regression analyses was in two steps. First, all variables including age, gender, BMI, smoking, hypertension, stroke, coronary artery disease, IPAQ levels, sleep quality (PSQI scores), and depressive symptoms (BDI scores) were individually examined in association with excessive daytime sleepiness. Secondly, a multivariate logistic regression analysis was performed in a stepwise regression model. Epworth sleepiness scale (ESS) scores (differences between values obtained after two years and baseline) were compared using analysis of variance. Statistical analysis was carried out using SPSS for Windows, version 17.0. Statistical significance was set at $p<0.05$.

\section{Results}

Clinical and demographic variables are depicted in Table 1. One hundred forty five patients, 87 women and 58 men, aged from 40 to 60 completed initial evaluation and follow-up. Fifty-one patients (35.2\%) had excessive daytime sleepiness (ESS>10). At baseline, men had more excessive daytime sleepiness than women (Fisher exact test, 52.9\% vs 32.9, $\mathrm{p}=0.02$ ). Arterial hypertension was found in 108 cases (74\%) and 10 individuals (6.9\%) developed hypertension after two years. Cardiac abnormalities were present in 44 patients (30\%) and this was unaltered after two years. Stroke was found in 14 individuals (10\%) at baseline and 8 (6\%) developed a new stroke after two years (Table 1).

Logistic regression analysis showed that male gender was associated with excessive daytime sleepiness ( $\mathrm{OR}=2.28, \mathrm{Cl}=1.13-4.59, \mathrm{p}=0.02)$. A higher comorbidity index tended to be associated with excessive daytime sleepiness (Table 2). Stepwise multiple regression analysis showed that a sedentary lifestyle was independently associated with excessive daytime sleepiness $(\mathrm{OR}=0.52, \mathrm{Cl}=0.29-0.92$, $\mathrm{p}=0.02$; Table 2).

After two years of follow-up, 75 patients (51.7\%) remained at the same level of daytime sleepiness, $41(28.3 \%)$ had higher levels of sleepiness levels and 29 (20.0\%) showed reduced levels of daytime sleepiness. Patients with an initial sedentary lifestyle evolved with more daytime sleepiness and those more active evolved with less daytime sleepiness as compared to the more active (Figure 2, Wilcoxon, $\mathrm{p}<0.05)$. Overall, patients improved the level of physical activity after two years (Figure 1).

Analysis of factors influencing the variation of sleepiness (changes from baseline of ESS scores) showed that women developed higher levels of daytime sleepiness than men (Figure 3, ANCOVA, $p=0.01$ ). Patients with stroke also evolved with higher levels of sleepiness after two years (Figure 3, ANCOVA, $p=0.03$ ). Individuals with sedentary lifestyle at baseline tended to evolve with worse daytime sleepiness (Figure 4, ANCOVA, $p=0.09$ ). Examination of gender differences showed that 
Table 1. Comparisons between patients with and without excessive daytime sleepiness (Epworth Sleepiness Scale>10) after two years

\begin{tabular}{|l|c|c|c|}
\hline & $\begin{array}{c}\text { With EDS } \\
(\mathbf{N = 5 1 )}\end{array}$ & $\begin{array}{c}\text { Without EDS } \\
(\mathbf{N = 1 2 1 )}\end{array}$ & P values \\
\hline Clinical/demographic variables & & & \\
\hline Gender M/F (N/\%) & $27(53 \%) / 24(47 \%)$ & $31(33 \%) / 63(67 \%)$ & a 0.22 \\
\hline Disease duration Mean (SD) (years) & $10.8(6.2)$ & $12.2(8.0)$ & b 0.22 \\
\hline Arterial hypertension N (\%) & $67(71 \%)$ & $41(80 \%)$ & a 0.31 \\
\hline Coronariopathy N (\%) & $12(23 \%)$ & $32(34 \%)$ & a 0.25 \\
\hline Stroke N (\%) & $2(4 \%)$ & $12(13 \%)$ & a 0.13 \\
\hline Alcohol use N (\%) & $4(8 \%)$ & $12(13 \%)$ & a 0.27 \\
\hline Smokers N (\%) & $4(8 \%)$ & $5(5 \%)$ & a 0.39 \\
\hline Antidepressants N (\%) & $18(25 \%)$ & $15(15 \%)$ & a 0.43 \\
\hline Behavioral scales & & & a 0.31 \\
\hline CCI N (\%) & & $15(16 \%)$ & \\
\hline = & $6(12 \%)$ & $15(16 \%)$ & \\
\hline 1 & $3(6 \%)$ & $64(58 \%)$ & \\
\hline 2 & $42(82 \%)$ & $10.6(8.8)$ & b 0.31 \\
\hline Beck Depression Inventory Mean (SD) & $9.4(8.6)$ & & a 0.85 \\
\hline IPAQ N (\%) & & $72(59 \%)$ & \\
\hline Sedentary & $30(58 \%)$ & $31(25 \%)$ & \\
\hline Mildly active & $12(23 \%)$ & & \\
\hline
\end{tabular}

Abbreviations: M/F: Male/Famale; N(\%): Number of patients (percentage value); SD: Standard Desviation; CCI: Charlson Comorbidity Index; IPAQ: International Physical Activity Questionnaire; a Fisher's exact; b test $t$ test. ${ }^{*} P<0.05{ }^{* * P}<0.01$

physical activity level (IPAQ) was more influential for women than for men. The use of antidepressants or metformin was not associated with alterations of sleepiness severity after two years of follow-up.

\section{Discussion}

In this prospective cohort study of patients with $\mathrm{T} 2 \mathrm{D}$, excessive daytime sleepiness was common affecting approximately one third of the individuals. Excessive daytime sleepiness was independently associated with low levels of physical activity. Moreover, at follow-up (two-years), individuals with a sedentary lifestyle evolved with more severe daytime sleepiness. These findings are in partial agreement with a previous study showing that physical activity, social interaction and light exposure improve the degree of alertness [34]. To our knowledge, this is the first time that physical activity shows a positive influence in daytime sleepiness in the long-run. Interestingly, daytime sleepiness evolved with more severity and physical activity was more beneficial in female patients.

Previously, a cross sectional survey involving veterans with T2D showed that sleepiness was predictive of being sedentary [37]. Possibly, promoting exercise interrupts this chain of events or bilateral relationship between sleepiness and sedentary life.

In this study, at baseline, men presented more daytime sleepiness. Possibly, this is related to the presence of OSA more common in male gender. In agreement with our findings, sex differences were described in T2D: depression affected more women and lack of exercise and degree of apnea were more frequent in men [35]. Previously, female gender was 
Table 2. Binary logistic regression analysis of factors associated with excessive daytime sleepiness (Epworth Sleepiness Scale>10)

\begin{tabular}{|l|c|c|}
\hline \multirow{2}{*}{ Model I } & \multicolumn{2}{|c|}{ Excessive Daytime Sleepiness } \\
\cline { 2 - 3 } Gender & OR (95\% Cl) & p Value \\
\hline Age & $2.28[1.13-4.59]$ & $0.02^{*}$ \\
\hline Stroke & $0.95[0.89-1.01]$ & 0.15 \\
\hline Arterial hypertension & $0.27[0.05-1.28]$ & 0.10 \\
\hline Coronariopathy & $1.65[0.72-3.76]$ & 0.23 \\
\hline Alcohol use & $0.59[0.27-1.29]$ & 0.19 \\
\hline Insulin therapy & $0.53[0.14-1.97]$ & 0.34 \\
\hline Pittsburgh Sleep Quality Index & $1.28[0.65-2.55]$ & 0.46 \\
\hline Body mass index & $1.03[0.90-1.07]$ & 0.18 \\
\hline Neck circumference & $1.01[0.94-1.08]$ & 0.72 \\
\hline Beck Depression Inventory & $1.02[0.93-1.10]$ & 0.64 \\
\hline Waist circumference & $0.98[0.94-1.02]$ & 0.42 \\
\hline Waist-to-hip ratio & $0.93[0.86-1.0]$ & 0.05 \\
\hline IPAQ & $1.73[0.04-94.2]$ & 0.73 \\
\hline Charlson Comorbidity Index & $0.98[0.04-2.07]$ & 0.96 \\
\hline Model II & $1.27[1.00-1.63]$ & 0.05 \\
\hline Gender & & \\
\hline IPAQ & $2.09[1.02-4.26]$ & $0.04^{*}$ \\
\hline Abbrevitions:PAQ: & $0.02^{*}$ \\
\hline
\end{tabular}

Abbreviations: IPAQ: International Physical Activity Questionnaire.

Model I -In this unadjusted model, clinical demographic variables and behavioral scales were analyzed individually. Model II - In this model, data were adjusted for age, gender, presence of stroke, coronariopathy, waist circumference, IPAQ levels e Charlson Comorbidity Index in a stepwise regression model.

$* P<0.05 * * P<0.01$

associated with worse daytime sleepiness [4, 36]. In partial agreement, this study showed that women evolved with more daytime sleepiness after two years. Importantly, a better level of physical activity was more influential for women. Similar to our findings, lack of exercise, depression and degree of apnea were predictive of daytime sleepiness in T2D [35]. Also, in the latter study, the majority of patients were of female gender; however, sex differences related to risk factors for excessive daytime sleepiness were not found. All this evidence indicates that female diabetic patients are a more "at risk" population for daytime sleepiness.

Theoretically, inflammatory cytokines are involved in the genesis of daytime sleepiness. As a controversy, physical activity both increases [38] and reduces [39] inflammatory factors. Physical activity may improve daytime sleepiness by interference with multiple factors e.g. inflammatory markers, improvement of sleep quality, alignment of circadian factors or other unclarified factors.

In this study, after two years of follow-up, the number of patients that became more active was increased. A positive influence on lifestyle may have been secondary to both: physician's counseling to physical activity as a therapeutic measure and the constant focus on physical activity related to the study. 
Figure 1: The number of patients with a sedentary lifestyle was reduced after two years.

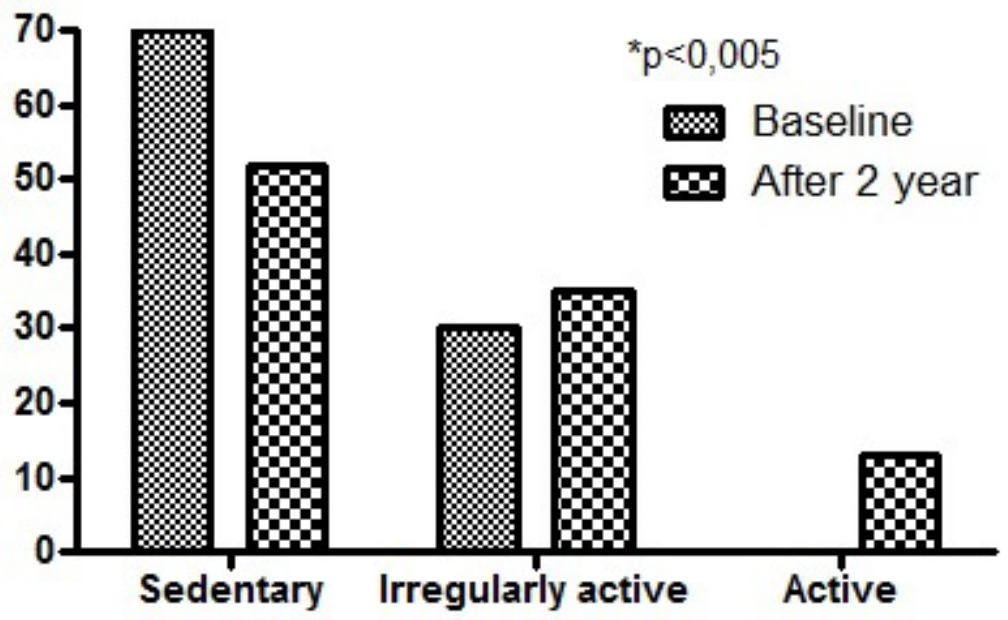

Figure 2: Patients with a sedentary lifestyle evolved with more daytime sleepiness and in opposition, the more physically active evolved with less daytime sleepiness.

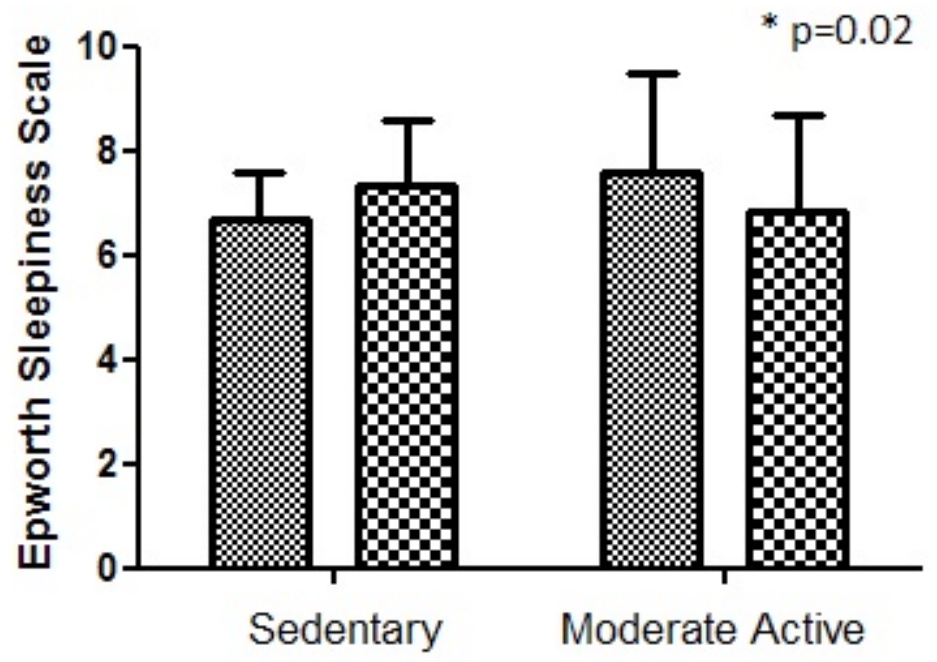

m Baseline

After 2 years

Regarding the role of comorbidities, according to the present data, depressive symptoms were not associated with increased sleepiness or with worsening of daytime sleepiness. A trend of association between comorbidity severity and excessive daytime sleepiness was found. Patients with stroke developed greater levels of excessive daytime sleepiness and this is expected considering that brain lesions probably add to the other causes of excessive daytime sleepiness. Patients with stroke are more subjected to circadian changes [40] and poor sleep quality $[41,42]$ adding to the causes of excessive daytime sleepiness. Therefore, physical activity should be highly recommended in patients with T2D and stroke in order to improve daytime sleepiness.

The ESS is a measure of sleepiness commonly 
Figure 3: After two years, women and individuals with stroke showed more daytime sleepiness.
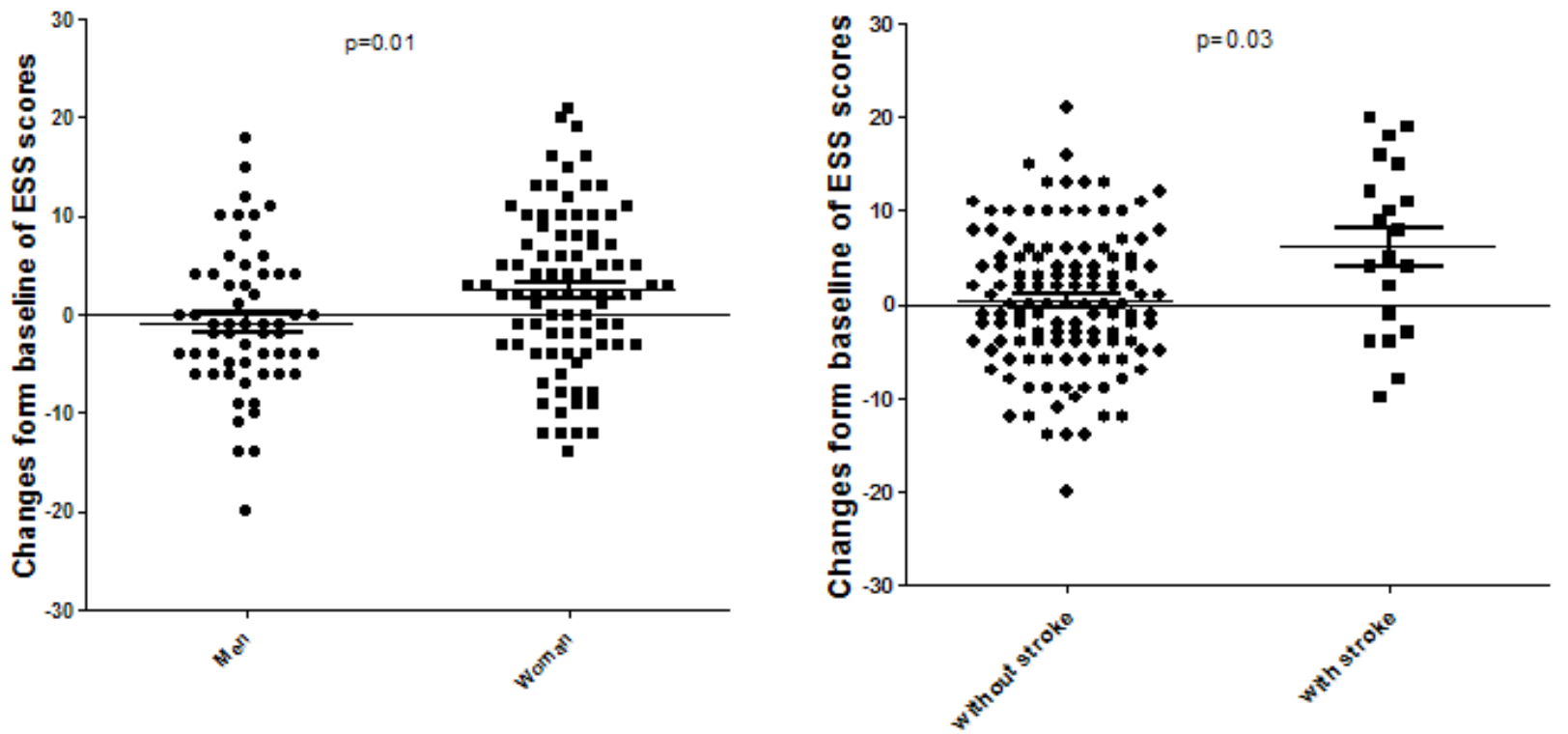

Figure 4: Overall, patients with a sedentary life style evolved with worsening of sleepiness.

All patients

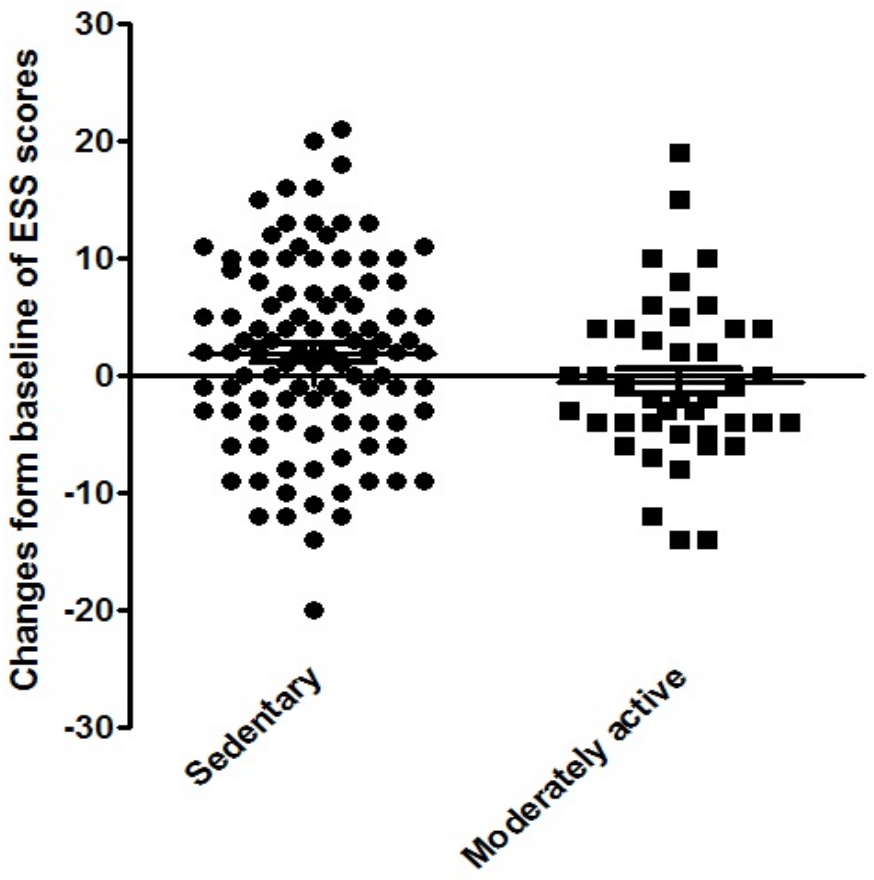


used in sleep research and clinical practice $[43,44]$. Subjective ratings of sleepiness are sensitive and valid indicators of sleepiness that are suitable for clinical studies. Previous evidence shows that poor agreement between the various measures of sleepiness exist: both subjective and objective, may reflect the multidimensional nature of sleepiness. In this sense, a comprehensive evaluation of sleepiness may require multiple measures $[43,45,46]$. Despite the fact that sleep alterations have been frequently connected with T2D, it has been noted that glycemic variation, as well as poor glycemic control found in type 1 diabetes mellitus may also affect the sleepwake cycle [47].

In this study, the use of metformin was not associated with daytime sleepiness or with the aggravation of these symptoms after two years. Also, insulin was non-influential to both daytime sleepiness and the variation of these symptoms after two years. Previously, metformin therapy was associated with a longer sleep duration and better sleep efficiency potentially ameliorating excessive daytime sleepiness [48]. This study was not designed to investigate the influence of metformin and insulin on daytime somnolence.

Limitations are acknowledged. The diagnosis of obstructive sleep apnea was not confirmed or excluded. The conclusions of this study must be limited to subjective sleepiness, which is a sensitive and valid measure suitable for clinical studies; however, it does not always correlate to measures of objective sleepiness. Subjective measures such as the ESS reflect a different construct and do not always correlate with objective sleep measures [49].

In summary, patients with T2D frequently have daytime sleepiness and women evolve with more severity being a "at risk" population. Better levels of physical activity are associated with a positive evolution of daytime sleepiness and are more beneficial for women. The implementation of physical exercise is a possible break of chain improving sleep-wake alterations and comorbidities in T2D.

\section{Conflict of interest declaration}

I certify that the study submitted has not received any financial support from pharmaceutical industry or other commercial source and none of the authors have any first-degree relative or possess a financial interest in the subject approached in the manuscript.

\section{References}

1. Empana JP, Dauvilliers Y, Dartigues JF, Ritchie K, Gariepy J, Jouven $X$, et al. Excessive daytime sleepiness is an independent risk indicator for cardiovascular mortality in community-dwelling elderly: the three city study. Stroke. 2009;40(4):1219-24

2. Ronksley PE, Hemmelgarn BR, Heitman SJ, Flemons WW, Ghali WA, Manns B, et al. Excessive daytime sleepiness is associated with increased health care utilization among patients referred for assessment of OSA. Sleep. 2011;34(3):363-70.

3. Gooneratne NS, Richards KC, Joffe M, Lam RW, Pack F, Staley $B$, et al. Sleep disordered breathing with excessive daytime sleepiness is a risk factor for mortality in older adults. Sleep. 2011;34(4):435-42.

4. Medeiros C, Bruin V, Ferrer D, Paiva T, Montenegro Junior R, Forti $A$, et al. Excessive daytime sleepiness in type 2 diabetes. Arq Bras Endocrinol Metabol. 2013;57(6):425-30

5. Kreier F, Kalsbeek A, Sauerwein HP, Fliers E, Romijn JA, Buijs RM. "Diabetes of the elderly" and type 2 diabetes in younger patients: possible role of the biological clock. Exp Gerontol. 2007;42(1-2):22-7.

6. Fernandez-Mendoza J, Vgontzas AN, Kritikou I, Calhoun SL, Liao D, Bixler EO. Natural history of excessive daytime sleepiness: role of obesity, weight loss, depression, and sleep propensity. Sleep. 2015;38(3):351-60.

7. Lopes LA, Lins Cde M, Adeodato VG, Quental DP, de Bruin PF, Montenegro RM, Jr., et al. Restless legs syndrome and quality of sleep in type 2 diabetes. Diabetes Care. 2005;28(11):2633-6.

8. Kent BD, Grote L, Ryan S, Pepin JL, Bonsignore MR, Tkacova R, et al. Diabetes mellitus prevalence and control in sleep-disordered breathing: the European Sleep Apnea Cohort (ESADA) study. Chest. 2014;146(4):982-90.

9. Osonoi Y, Mita T, Osonoi T, Saito M, Tamasawa A, Nakayama $S$, et al. Morningness-eveningness questionnaire score and metabolic parameters in patients with type 2 diabetes mellitus. Chronobiol Int. 2014;31(9):1017-23.

10. Peng B, Chen Z, Ma L, Dai Y. Cerebral alterations of type 2 diabetes mellitus on MRI: A pilot study. Neurosci Lett. 2015;606:100-5

11. Wang C, Fu K, Liu H, Xing F, Zhang S. Brain structural changes and their correlation with vascular disease in type 2 diabetes mellitus patients: a voxel-based morphometric study. Neural Regen Res. 2014;9(16):1548-56. 
12. Lee SA, Lee GH, Chung YS, Kim WS. Clinical, polysomnographic, and CPAP titration features of obstructive sleep apnea: Mixed versus purely obstructive type. J Neurol Sci. 2015;355(1-2):150-4.

13. Ceccato F, Bernkopf E, Scaroni C. Sleep apnea syndrome in endocrine clinics. J Endocrinol Invest. 2015;38(8):827-34.

14. Wu Y, Zhai L, Zhang D. Sleep duration and obesity among adults: a meta-analysis of prospective studies. Sleep Med. 2014;15(12):1456-62

15. Lou P, Zhang P, Zhang L, Chen P, Chang G, Zhang N, et al. Effects of sleep duration and sleep quality on prevalence of type 2 diabetes mellitus: A 5-year follow-up study in China. Diabetes Res Clin Pract. 2015;109(1):178-84

16. Daniele TM, Bruin VM, Oliveira DS, Pompeu CM, Forti AC. Improving patient's independence and treating depressive symptoms can promote physical activity in diabetic patients.. Arq Bras Endocrinol Metabol. 2013;57(8):665-6.

17. Todea DA, Postolache $P$, Coman AC, Rosca LE. Relationship between type 2 diabetes mellitus and obstructive sleep apnea syndrome. Chest. 2014;145(3 Suppl):576A.

18. Lecomte $P$, Criniere L, Fagot-Campagna A, Druet C, Fuhrman C. Underdiagnosis of obstructive sleep apnoea syndrome in patients with type 2 diabetes in France: ENTRED 2007. Diabetes Metab. 2013;39(2):139-47.

19. Bonanni E, Tognoni G, Maestri M, Salvati N, Fabbrini M, Borghetti $D$, et al. Sleep disturbances in elderly subjects: an epidemiological survey in an Italian district. Acta Neurol Scand. 2010.

20. Daniele TM, de Bruin VM, de Oliveira DS, Pompeu CM, Forti AC. Associations among physical activity, comorbidities, depressive symptoms and health-related quality of life in type 2 diabetes. Arquivos brasileiros de endocrinologia e metabologia. 2013;57(1):44-50

21. Ryan AS. Exercise in aging: its important role in mortality, obesity and insulin resistance. Aging health. 2010;6(5):551-63.

22. Crawford AG, Cote C, Couto J, Daskiran M, Gunnarsson C, Haas K, et al. Prevalence of obesity, type II diabetes mellitus, hyperlipidemia, and hypertension in the United States: findings from the GE Centricity Electronic Medical Record database. Population health management. [Research Support, Non-U.S. Gov't]. 2010;13(3):151-61.

23. Reichert J, Araujo AJ, Goncalves CM, Godoy I, Chatkin JM, Sales MP, et al. Smoking cessation guidelines--2008. J Bras Pneumol. 2008;34(10):845-80

24. Qureshi Al, Suri MF, Kirmani JF, Divani AA. Prevalence and trends of prehypertension and hypertension in United States: National Health and Nutrition Examination Surveys 1976 to 2000. Medical science monitor : international medical journal of experimental and clinical research. [Research Support, Non-U.S. Gov't]. 2005;11(9):CR403-9

25. Charlson ME, Pompei P, Ales KL, MacKenzie CR. A new method of classifying prognostic comorbidity in longitudinal studies: development and validation. J Chronic Dis. 1987;40(5):373-83.
26. Daniele TM, Bruin VM, Forte AC, Oliveira DS, Pompeu CM, Bruin PF. The relationship between physical activity, restless legs syndrome, and health-related quality of life in type 2 diabetes. Endocrine. 2013;44(1):125-31.

27. Beck AT, Ward $\mathrm{CH}$, Mendelson M, Mock J, Erbaugh J. An inventory for measuring depression. Arch Gen Psychiatry. 1961;4:561-71.

28. Gorenstein C, Andrade L, Vieira Filho AH, Tung TC, Artes R. Psychometric properties of the Portuguese version of the Beck Depression Inventory on Brazilian college students. J Clin Psychol. 1999;55(5):553-62.

29. Bertolazi AN, Fagondes SC, Hoff LS, Dartora EG, Miozzo IC, de Barba ME, et al. Validation of the Brazilian Portuguese version of the Pittsburgh Sleep Quality Index. Sleep Med. 2011;12(1):70-5.

30. Bassett DR. International physical activity questionnaire: 12 -country reliability and validity. Med Sci Sports Exerc. 2003;35(8):1396.

31. Hallal PC, Victora CG, Wells JC, Lima RC. Physical inactivity: prevalence and associated variables in Brazilian adults. Med Sci Sports Exerc. 2003;35(11):1894-900.

32. Gutierrez-Repiso C, Soriguer F, Rojo-Martinez G, Garcia-Fuentes E, Valdes S, Goday A, et al. Variable patterns of obesity and cardiometabolic phenotypes and their association with lifestyle factors in the Di@bet.es study. Nutr Metab Cardiovasc Dis. 2014;24(9):947-55.

33. Johns MW. A new method for measuring daytime sleepiness: the Epworth sleepiness scale. Sleep. 1991;14(6):540-5.

34. Akerstedt T, Anund A, Axelsson J, Kecklund G. Subjective sleepiness is a sensitive indicator of insufficient sleep and impaired waking function. J Sleep Res. 2014;17.

35. Basta M, Lin HM, Pejovic S, Sarrigiannidis A, Bixler E, Vgontzas AN. Lack of regular exercise, depression, and degree of apnea are predictors of excessive daytime sleepiness in patients with sleep apnea: sex differences. J Clin Sleep Med. 2008;4(1):19-25.

36. Richter E, Blasco V, Antonini F, Rey M, Reydellet L, Harti K, et al. Sleep disorders among French anaesthesiologists and intensivists working in public hospitals: A self-reported electronic survey. Eur J Anaesthesiol. 2014;5

37. Chasens ER, Umlauf MG, Weaver TE. Sleepiness, physical activity, and functional outcomes in veterans with type 2 diabetes. Appl Nurs Res. 2009;22(3):176-82.

38. Chatzinikolaou A, Draganidis D, Avloniti A, Karipidis A, Jamurtas $A Z$, Skevaki $C L$, et al. The microcycle of inflammation and performance changes after a basketball match. J Sports Sci. 2014;32(9):870-82.

39. Alves Eda S, Ackel-D’Elia C, Luz GP, Cunha TC, Carneiro G, Tufik $S$, et al. Does physical exercise reduce excessive daytime sleepiness by improving inflammatory profiles in obstructive sleep apnea patients? Sleep Breath. 2013;17(2):505-10.

40. Cavalcanti PR, Campos TF, Araujo JF. Circadian and homeostatic changes of sleep-wake and quality of life in stroke: implications for neurorehabilitation. NeuroRehabilitation. 2013;32(2):337-43. 
41. Da Rocha PC, Barroso MT, Dantas AA, Melo LP, Campos TF. Predictive factors of subjective sleep quality and insomnia complaint in patients with stroke: implications for clinical practice. An Acad Bras Cienc. 2013;85(3):1197-206.

42. Bakken LN, Kim HS, Finset $A$, Lerdal A. Subjective sleep quality in relation to objective sleep estimates: comparison, gender differences and changes between the acute phase and the sixmonth follow-up after stroke. J Adv Nurs. 2014;70(3):639-50.

43. Kendzerska TB, Smith PM, Brignardello-Petersen R, Leung RS, Tomlinson GA. Evaluation of the measurement properties of the Epworth sleepiness scale: A systematic review. Sleep Med Rev. 2013;22.

44. Sil A, Barr G. Assessment of predictive ability of Epworth scoring in screening of patients with sleep apnoea. J Laryngol Otol. 2012;126(4):372-9.

45. Lee SJ, Kang HW, Lee LH. The relationship between the Epworth Sleepiness Scale and polysomnographic parameters in obstructive sleep apnea patients. Eur Arch Otorhinolaryngol. 2012;269(4):1143-7.

46. Killgore WD, Capaldi VF, 2nd, Guerrero ML. Nocturnal polysomnographic correlates of daytime sleepiness. Psychol Rep. 2012;110(1):63-72.

47.Barone MTU, Menna-Barreto L. Type I diabetes associated with sleep disorders. Sleep Science. 2009;2(2):96-8.

48. Kajbaf F, Fendri S, Basille-Fantinato A, Diouf M, Rose D, Jounieaux $V$, et al. The relationship between metformin therapy and sleep quantity and quality in patients with Type 2 diabetes referred for potential sleep disorders. Diabet Med. 2014;31(5):577-80.

49. Buysse DJ, Hall ML, Strollo PJ, Kamarck TW, Owens J, Lee L, et al. Relationships between the Pittsburgh Sleep Quality Index (PSQI), Epworth Sleepiness Scale (ESS), and clinical/ polysomnographic measures in a community sample. J Clin Sleep Med. 2008;4(6):563-71.

Publish in International Archives of Medicine

International Archives of Medicine is an open access journal publishing articles encompassing all aspects of medical science and clinical practice. IAM is considered a megajournal with independent sections on all areas of medicine. IAM is a really international journal with authors and board members from all around the world. The journal is widely indexed and classified Q2 in category Medicine. 